Research Article

\title{
Experimental Study on Acoustic Emission and Resistivity Response of Sandstone under Constant Amplitude Cyclic Loading
}

\author{
Kui Wang $\mathbb{D},{ }^{1}$ Xue Li $\mathbb{D},{ }^{2}$ Zheng Huang $\mathbb{D}^{1,2}$ and Mingjie Zhao $\mathbb{D}^{1}$ \\ ${ }^{1}$ Engineering Research Center of Diagnosis Technology of Hydro-Construction, Chongqing Jiaotong University, \\ Chongqing 400074, China \\ ${ }^{2}$ Chongqing Surveying and Design Institute of Water Resources, Electric Power and Architecture, Chongqing 400020, China
}

Correspondence should be addressed to Kui Wang; anhuiwk@163.com

Received 23 November 2020; Revised 5 February 2021; Accepted 22 February 2021; Published 9 March 2021

Academic Editor: Xiangxiong Kong

Copyright (c) 2021 Kui Wang et al. This is an open access article distributed under the Creative Commons Attribution License, which permits unrestricted use, distribution, and reproduction in any medium, provided the original work is properly cited.

\begin{abstract}
A lot of engineering practice shows that, during the construction and operation of rock mass projects, in addition to the static load, the rock is more subjected to cyclic load. Constant amplitude cyclic load is one of the simpler cyclic loading methods. The damage of rocks gradually accumulates under the action of periodic cyclic load, and finally, fatigue damage occurs, which affects the stability of the project. Therefore, it is necessary to study the mechanical properties of the rock under the action of constant amplitude cyclic load. Acoustic emission (AE) parameters and resistivity are both sensitive to the damage process of the rock and can well describe the damage evolution law of the rock. Under the action of constant amplitude cyclic loading, different loading conditions, different state specimens, and so on, factors will make a big difference to the AE signal and resistivity, such as the difference in stress amplitude, loading rate, and saturation. Therefore, in this paper, the typical sandstone in the Chongqing area is taken as the research object, the $\mathrm{AE}$ characteristics and resistivity characteristics of sandstone under different test conditions such as different stress amplitude, different loading frequency, and different saturation are tested, and the evolution of AE is found. It also has a three-stage rule: in the initial stage, the deformation is faster and the AE signal is strong; in the constant velocity stage, the deformation develops slowly and the AE signal is also stable; in the acceleration stage, the deformation develops sharply and the AE signal also becomes more intense. With the increase of cyclic loading stress amplitude, or the decrease of cyclic loading frequency, or the decrease of rock sample saturation, the acoustic emission signal generated in each cycle will be stronger. The resistivity as a whole shows a rapid decline in the loading phase and a rapid rebound in the unloading phase. The changes in resistivity at different stress amplitudes show differences in the first few cycles; the overall change trend of resistivity at different frequencies is consistent, but the rate of change increases with decreasing frequency, and the variation trend of resistivity is very different under different saturation.
\end{abstract}

\section{Introduction}

In practice, rock mass is often subjected to cyclic loading. As one of the relatively simple cyclic loading modes, the damage of rock under cyclic loading gradually accumulates until fatigue failure occurs, which affects the stability of the project. Therefore, it is of great practical value to study the damage law of rock under constant amplitude cyclic load to judge the stability of engineering rock mass.

As early as the 1930s, Obert and Duvall first discovered that there is acoustic emission (AE) activity in the process of rock compression, and then many scholars continue to study the $\mathrm{AE}$ characteristics in the process of rock failure [1]. For example, Ganne [2] carried out experimental research on AE characteristics of brittle rock in the process of failure and analyzed the accumulation of AE energy of rock. Shkuratnik et al. [3] studied the memory effect of AE of coal rock under triaxial cyclic loading. Rodríguez and Celestino [4] studied the crack propagation of granite and marble in combination with $\mathrm{AE}$ parameters and time-frequency characteristics. Wang et al. [5] made a detailed analysis of the AE characteristics of granite and sandstone during uniaxial compression. Jiang et al. [6] analyzed the AE characteristics of red sandstone during fatigue damage and discussed that the 
rationality of damage varies based on axial strain. Wang [7] studied the AE characteristics of conglomerate, sandstone, and mudstone under different stress conditions. Song [8] studied the AE characteristics corresponding to the evolution, stretching, and dislocation of rock deformation process in the deformation localization zone. The results show that the damage and failure process of rock must be accompanied by the generation of AE signal, which can characterize the damage evolution law of rock.

As an important electrical parameter of rock, the resistivity indicates the strength of rock conductivity. In 1942, Archie, an American logging engineer, obtained the relationship between resistivity and porosity of saturated sandstone samples using double logarithmic coordinates, which is the famous Archie formula. Since then, the research on rock resistivity characteristics has gradually developed, and the application of resistivity testing has developed from the interpretation of formation logging data to the study of rock deformation characteristics under loading [9-12]. For example, brace and orange [13] measured the resistivity changes of a variety of rocks under different constant amplitude and fracture water pressures through the bipolar method and studied the correlation between resistivity and deformation of loaded rocks; Chen and Lin [12] studied the electrical effect of rock under load through experiments and put forward the state equation of rock failure law. Kahtaman et al. [14] conducted uniaxial compression tests and tensile tests on igneous rocks and found that both compressive strength and tensile strength are linearly related to resistivity. Ji et al. [15] analyzed resistivity changes during rock deformation and failure based on the test results of resistivity testing under cyclic loading conditions and indirectly linked the resistivity and damage variables through the secant modulus. Song et al. [16] conducted constant amplitude cyclic loading and graded cyclic loading experiments on limestone and found that the change of resistivity can better reflect the development of microcracks in the rock sample under this state. Tu et al. [17] derived the expression of the ratio of the stress to the peak stress of the rock corresponding to the sudden change of the resistivity before the rock rupture under the load based on the evolution law of the resistivity during the deformation and failure of the rock under load. The above studies show that the closure of rock pores and the expansion of microcracks will affect the electrical conductivity of the rock. Therefore, the damage state of the rock can be judged through the change of resistivity, and the mechanical properties of the rock can be inverted.

In summary, $\mathrm{AE}$ parameters and resistivity are both sensitive parameters in the process of rock deterioration and damage. At present, although certain studies have been carried out on the $\mathrm{AE}$ characteristics and resistivity of rocks, there is still a lack of research on the correlation between rock wave electrical characteristic parameters and stress and the comprehensive use of wave electrical testing techniques to study rock damage evolution. In view of this, this paper has studied the change law of sandstone AE parameters and resistivity under constant amplitude cyclic loading and provides a basic foundation for further analysis of rock damage evolution under cyclic loading through wave-electric combined testing technology.

\section{Experimental Device Design and Testing}

2.1. Experimental Device Design. This test mainly studied the $\mathrm{AE}$ characteristics and resistivity characteristics of sandstone under constant amplitude cyclic loading. AE test system and resistivity test system were used in conjunction with rock pressure testing machine to carry out AE-resistivity-stress simultaneous test. As shown in Figure 1, the RMT-301 rock mechanics test system was used as the loading system, SAEU2S AE system was used for AE testing, and M300 data acquisition system was used for resistivity testing. By designing a fixing device, the AE probe and electrode sheet were fixed in the experimental device, so as to achieve the purpose of the AE-resistivity-stress synchronous test.

2.2. Sample Preparation and Screening. The sandstone specimens this time were taken from the same sandstone rock mass in the Chongqing area. The drilled sandstone specimens were processed into standard cylindrical specimens of $\Phi 50 \mathrm{~mm} \times 100 \mathrm{~mm}$ by the wet processing method. As shown in Figure 2, the two end faces are flat. The degree error is less than $0.02 \mathrm{~mm}$. In order to minimize the discreteness of the test results caused by the individual differences of the specimens, the diameter, height, mass, and wave velocity of the specimens were measured, and the sandstone specimens with the closest parameters such as density, geometric size, and wave velocity were selected for grouping and numbering, as shown in Table 1. The first group of samples (DZ01-DZ 06) was used for static uniaxial compression test, the second group of samples (SX01, SX 01-1, SX 01-2- SX 03, SX 03-1, and SX 03-2) was used for constant amplitude cyclic loading test with different stress amplitude, the third group of samples (PL01, PL01-1, PL012-PL03, PL03-1, and PL03-2) was used for constant amplitude cyclic loading test with different frequency, and the fourth group of samples (BH01, BH01-1, BH01-2-BH03, BH03-1, and BH03-2) was used for cyclic loading test of different water saturation states (saturated state, natural state, and drying state).

2.3. Experimental Process. First, a uniaxial compression test was performed to obtain the uniaxial compressive strength of the specimen. Since the upper limit and lower limit of the load in the constant amplitude cyclic loading test are determined based on the stress, the axial force is used as the control parameter during the uniaxial compression test, which can maintain the consistency before and after the experiment. The average loading rate is set. It is $0.5 \mathrm{kN} / \mathrm{s}$.

The constant amplitude cyclic loading and unloading test adopted the axial force to control, and the loading was carried out in two stages: the first stage was the linear loading stage, and the axial stress was loaded from zero to the average stress $(\sigma \mathrm{MAX}+\sigma \mathrm{min}) / 2$ at the rate of $0.5 \mathrm{kN} / \mathrm{s}$; the second stage was the cyclic loading stage, in which the cyclic load was applied from the average stress until the fatigue 


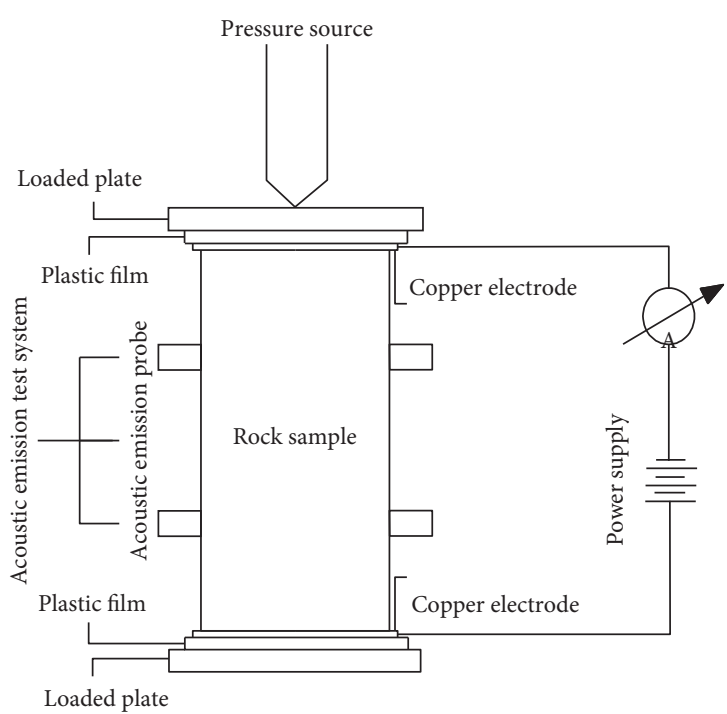

(a)

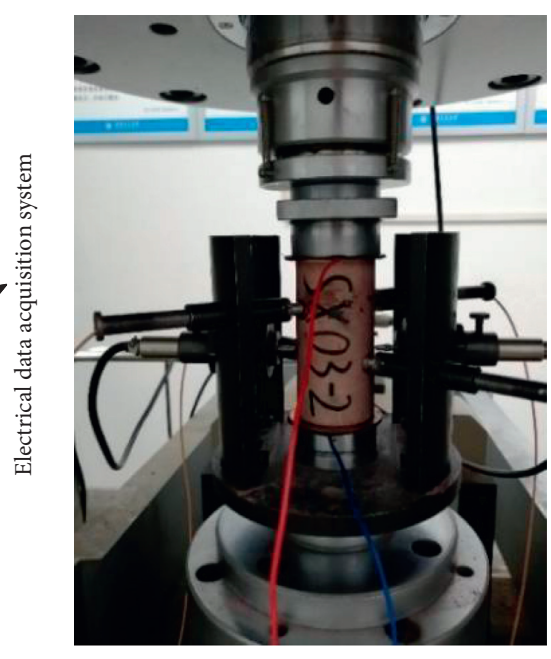

(b)

Figure 1: Experimental device. (a) Design of test system. (b) Acoustic emission-resistivity-stress synchronous test.

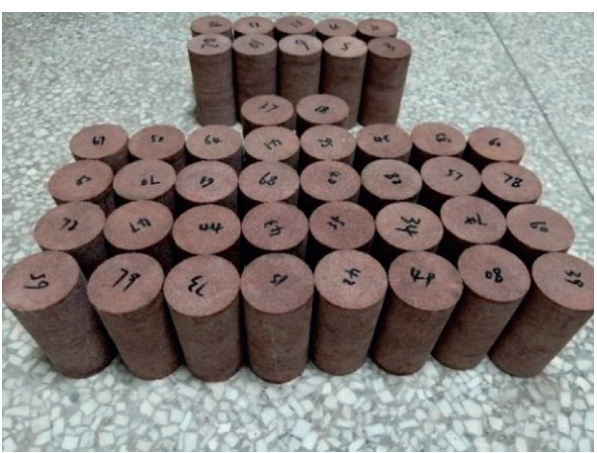

Figure 2: Sandstone specimen.

failure of the specimen occurs, and the loading waveform was a sine wave, as shown in Figure 3.

In order to reduce the influence caused by the discreteness of the samples, parallel tests of three samples were carried out under each test condition. The specific experimental conditions are as follows:

(1) Study on the influence of stress amplitude: the stress amplitude is changed by using the same lower limit stress ratio (i.e., the ratio of the lower limit stress value $\sigma \_$min to the compressive strength value $\sigma_{-}$c) and the different upper limit stress ratio. This experiment uses three different stress amplitude ratios: $20 \%-80 \%, 20 \%-85 \%$, and $20 \%-90 \%$. Three specimens were used for each group of stress ratio, and the average loading and unloading frequency was set to $0.2 \mathrm{HZ}$.

(2) Research on the influence of loading frequency: this cyclic loading test used three different frequencies $(0.1 \mathrm{~Hz}, 0.2 \mathrm{HZ}$, and $0.5 \mathrm{HZ})$, the upper limit stress ratio was $80 \%$, and the lower limit stress ratio was $20 \%$.
(3) Research on the influence of saturated sandstone: three different saturated sandstone samples (saturated, natural, and dried) were used for the constant amplitude cyclic loading test. The loading frequency is $0.2 \mathrm{HZ}$. The upper limit stress ratio was $80 \%$. The lower limit stress ratio was $20 \%$. The sample was saturated with water for 24 hours with a vacuum saturated machine to make a saturated test piece, and the sample was placed in an oven at a constant temperature of $105^{\circ} \mathrm{C}$ for 48 hours to make a dry test piece.

\section{Analysis of Acoustic Emission Response Characteristics of Sandstone under Constant Amplitude Cyclic Loading}

The number of ringing counts generated inside the rock per unit time can reflect the damage state of the internal structure of the rock. The more the counts, the more serious the rock damage, and the opposite, the lighter the rock damage. Therefore, this paper mainly used AE ringing counting to explore the AE characteristics of sandstone.

3.1. Acoustic Emission Characteristics of Sandstone under Different Stress Amplitudes. According to the test results, the axial force-time-ringing count relationship curve of typical sandstone samples under different stress amplitude conditions was drawn, as shown in Figure 4. In the initial stage of cyclic loading, the sandstone deformed quickly, the $\mathrm{AE}$ activity was strong, and the AE ringing count was large; in the isokinetic development stage, the AE signals of almost the same size were generated in each cycle, but the $\mathrm{AE}$ activity weakened and the ringing count reduced, which indicated that the upper limit stress reaches the yield strength of rock, and a small amount of plastic damage was produced in each cycle; during the accelerated failure stage, 
TABLE 1: Grouping of test pieces.

\begin{tabular}{|c|c|c|c|c|c|c|}
\hline Grouping & Specimen number & Diameter $(\mathrm{mm})$ & Height (mm) & Duality (g) & Density $\left(\mathrm{g} / \mathrm{cm}^{3}\right)$ & Velocity $(\mathrm{km} / \mathrm{s})$ \\
\hline \multirow{6}{*}{ No. 1} & DZ01 & 49.29 & 100.30 & 451.6 & 2.36 & 2.564 \\
\hline & DZ02 & 49.40 & 100.22 & 455.5 & 2.37 & 2.525 \\
\hline & DZ03 & 49.45 & 100.01 & 454.8 & 2.37 & 2.564 \\
\hline & DZ04 & 49.43 & 99.86 & 456.2 & 2.38 & 2.538 \\
\hline & DZ05 & 49.38 & 100.53 & 456.1 & 2.37 & 2.584 \\
\hline & DZ06 & 49.44 & 99.70 & 449.8 & 2.35 & 2.532 \\
\hline \multirow{9}{*}{ No. 2} & SX01 & 49.38 & 99.18 & 452.1 & 2.38 & 2.571 \\
\hline & SX01-1 & 49.30 & 99.76 & 453.4 & 2.38 & 2.500 \\
\hline & SX01-2 & 50.36 & 100.03 & 468.4 & 2.35 & 2.513 \\
\hline & SX02 & 49.40 & 99.14 & 453.3 & 2.39 & 2.598 \\
\hline & SX02-1 & 49.50 & 99.67 & 451.8 & 2.36 & 2.538 \\
\hline & SX02-2 & 50.21 & 99.96 & 469.8 & 2.37 & 2.525 \\
\hline & SX03 & 49.41 & 99.59 & 454.2 & 2.38 & 2.538 \\
\hline & SX03-1 & 49.26 & 99.94 & 452.5 & 2.38 & 2.506 \\
\hline & SX03-2 & 49.35 & 99.17 & 452.8 & 2.39 & 2.604 \\
\hline \multirow{9}{*}{ No. 3} & PL01 & 49.40 & 100.06 & 451.3 & 2.35 & 2.500 \\
\hline & PL01-1 & 49.50 & 100.16 & 457.7 & 2.38 & 2.525 \\
\hline & PL01-2 & 49.42 & 98.89 & 451.2 & 2.38 & 2.591 \\
\hline & PL02 & 49.38 & 99.18 & 452.1 & 2.38 & 2.571 \\
\hline & PL02-1 & 49.30 & 99.76 & 453.4 & 2.38 & 2.500 \\
\hline & PL02-2 & 50.36 & 100.03 & 468.4 & 2.35 & 2.513 \\
\hline & PL03 & 49.22 & 99.98 & 449.6 & 2.36 & 2.538 \\
\hline & PL03-1 & 49.48 & 100.01 & 456.1 & 2.37 & 2.577 \\
\hline & PL03-2 & 50.34 & 100.13 & 472.6 & 2.37 & 2.525 \\
\hline \multirow{9}{*}{ No. 4} & BH01 & 49.38 & 99.18 & 452.1 & 2.38 & 2.571 \\
\hline & BH01-1 & 49.30 & 99.76 & 453.4 & 2.38 & 2.500 \\
\hline & BH01-2 & 50.36 & 100.03 & 468.4 & 2.35 & 2.513 \\
\hline & BH02 & 49.45 & 99.92 & 456.5 & 2.38 & 2.551 \\
\hline & ВH02-1 & 49.43 & 100.23 & 456.2 & 2.37 & 2.625 \\
\hline & BH02-2 & 49.35 & 99.89 & 453.1 & 2.37 & 2.551 \\
\hline & ВH03 & 50.34 & 100.19 & 471 & 2.36 & 2.532 \\
\hline & ВH03-1 & 50.25 & 99.17 & 461.8 & 2.35 & 2.494 \\
\hline & BH03-2 & 49.51 & 99.78 & 451 & 2.35 & 2.475 \\
\hline
\end{tabular}

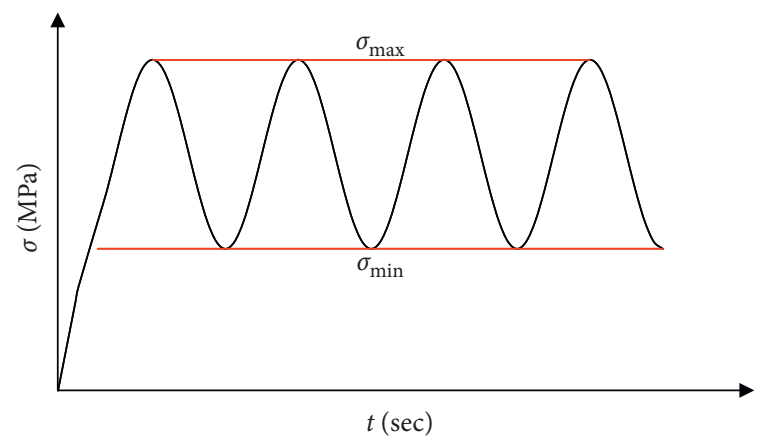

Figure 3: Cyclic loading path.

the rock deformation suddenly increased, the AE activity suddenly increased, and the ringing count increased exponentially until the rock failed.

At the same time, the test results also showed that the activity of AE is related to the stress level. With the increase of stress amplitude, the activity of AE increases, and the ringing count of $\mathrm{AE}$ is increased. At the same time, the test results also showed that the activity of $\mathrm{AE}$ is related to the stress level. With the increase of stress amplitude, the activity of $\mathrm{AE}$ increases, and the ringing count of $\mathrm{AE}$ is increased.
This is because with the increase of stress amplitude, the deformation of sandstone increases in each cycle, so the strain energy has a positive correlation with the stress amplitude. The generation of AE is actually the process that the accumulated strain energy is released to the outside in the form of a transient elastic wave. If the energy of $\mathrm{AE}$ is increased indirectly, the activity of $\mathrm{AE}$ is more obvious. In addition, the AE signals almost appear near the upper limit stress, which indicates that the upper limit stress is more sensitive to the generation of AE signals.

3.2. Acoustic Emission Characteristics of Sandstone under Different Loading Frequencies. According to the test results, the axial force-time-AE ringing count relationship curve of typical sandstone specimens under different loading frequency conditions was drawn, as shown in Figure 5. Under different loading frequencies, the $\mathrm{AE}$ response characteristics of sandstone are basically similar. In the initial cycle stage, the primary cracks and weak structural planes in the specimen produce damage and failure, the deformation of sandstone is large, the plastic damage is large, and the AE ringing count is large; after entering the fatigue stable period, the deformation is small, and the plastic damage produced 


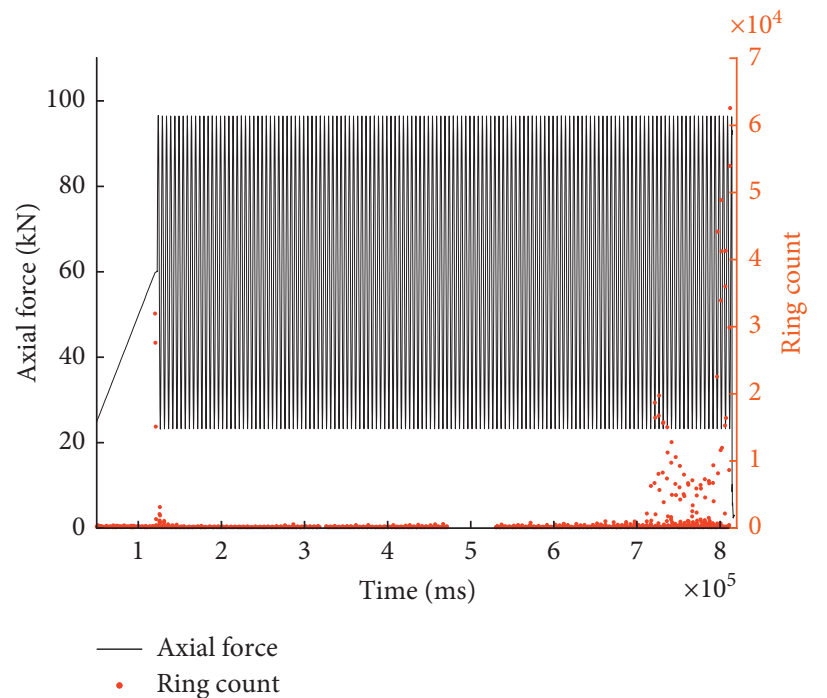

(a)

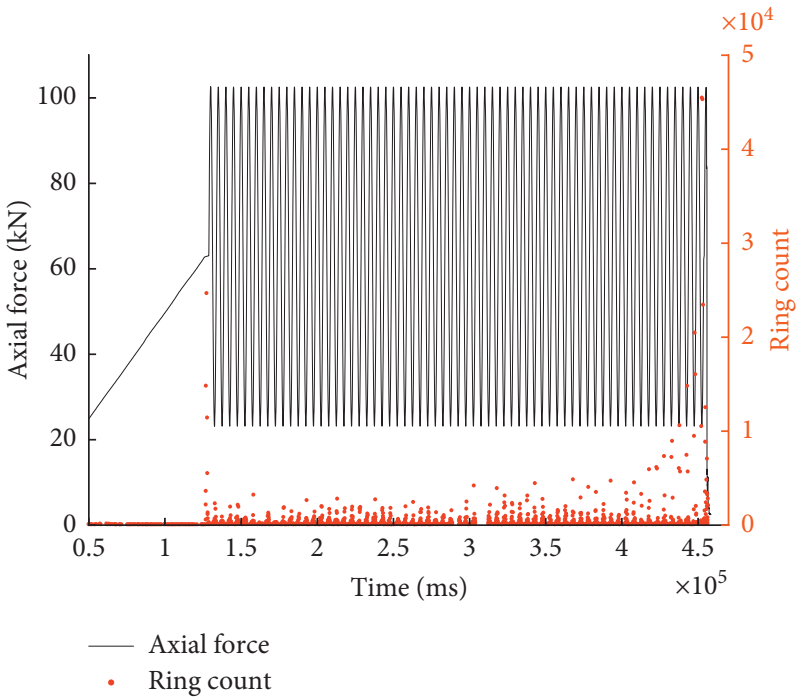

(b)

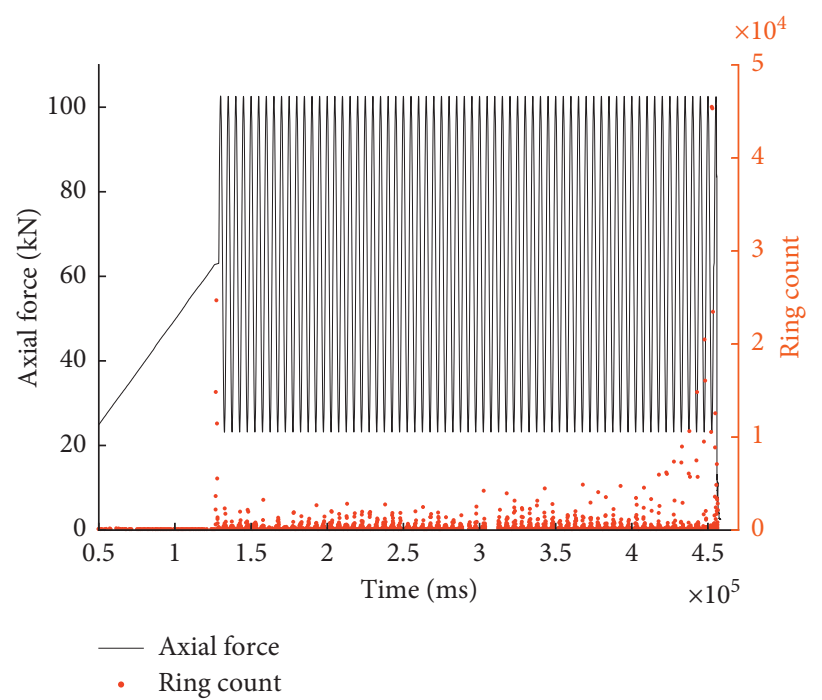

(c)

Figure 4: Evolution Law of acoustic emission of sandstone under different stress amplitudes. (a) Acoustic emission law of $20 \%-80 \%$ stress level. (b) Acoustic emission law of 20\%-85\% stress level. (c) Acoustic emission law of $20 \%-90 \%$ stress level.

by each cycle is small, so the $\mathrm{AE}$ ringing count is small, which lasts for a long time. Near the last few cycles of failure, that is, when the damage of rock has accumulated to a certain extent, the deformation of rock develops rapidly. In a few cycles, the strain reaches the limit deformation of rock. The macrocracks are connected and the rock is destroyed. At this stage, the AE activity increases sharply and the ringing count increases suddenly. These well reflect the failure process of the rock cycle.

The test results also showed that the higher the loading frequency, the weaker the AE signal generated in each cycle. This is because as the loading frequency increases, the cycle life of the rock is longer, and the strength of the rock will increase. However, the loading stress value was selected by the same standard, so this indirectly reduced the loading stress, resulting in the fact that the smaller the damage and deformation of the rock during each loading cycle, the longer the cycle period. The strength of the AE signal is directly related to the degree of damage inside the material. The more severe the material damage, the stronger the $\mathrm{AE}$ activity, and vice versa. Therefore, as the loading frequency increases, that is, while the cycle life of the rock increases, the $\mathrm{AE}$ activity during the cyclic loading process is correspondingly weakened.

3.3. Acoustic Emission Characteristics of Sandstone under Different Saturations. According to the test results, the axial force-time-AE ringing count relationship curve of three typical sandstone specimens under different water saturation was drawn, as shown in Figure 6. The AE signals of sandstone under different water saturation conditions are 


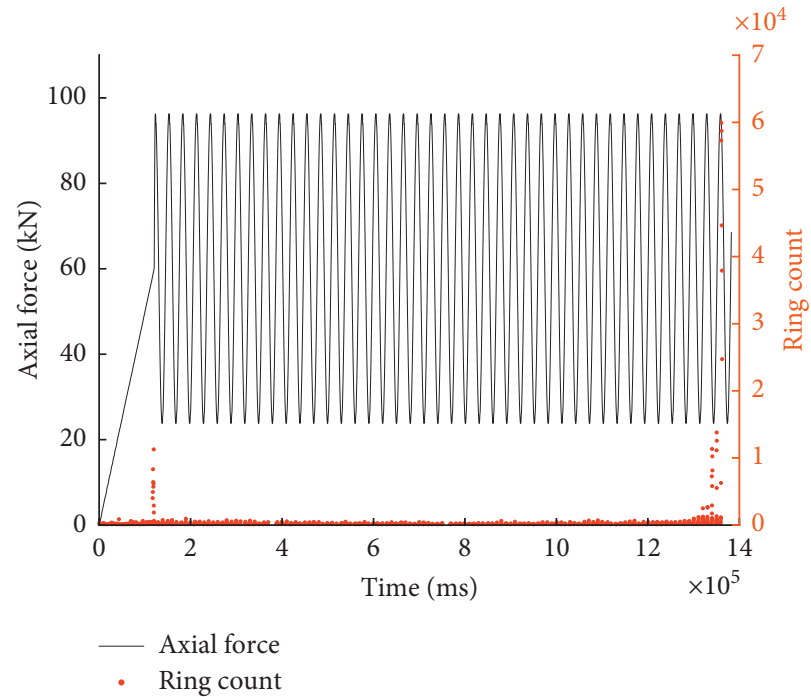

(a)

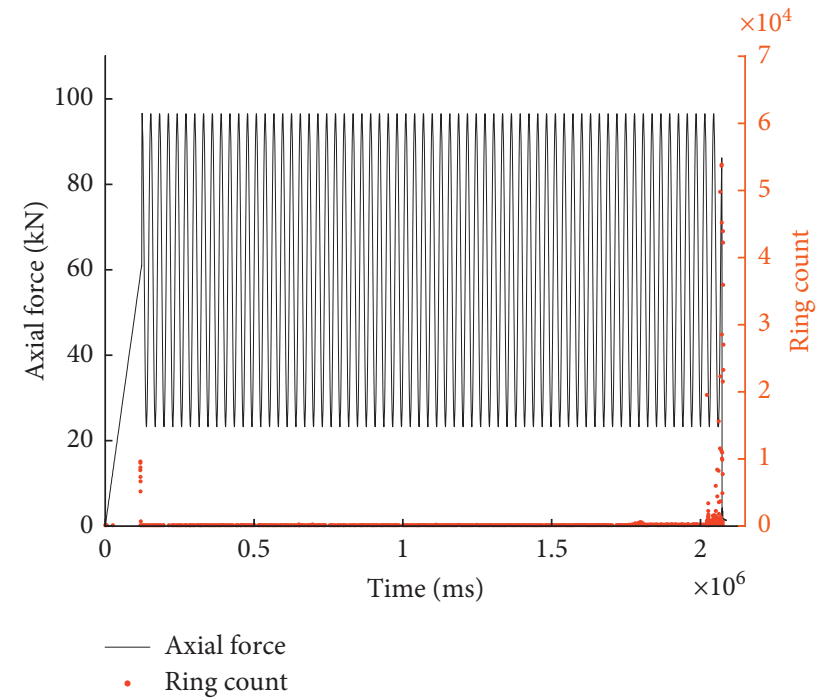

(b)

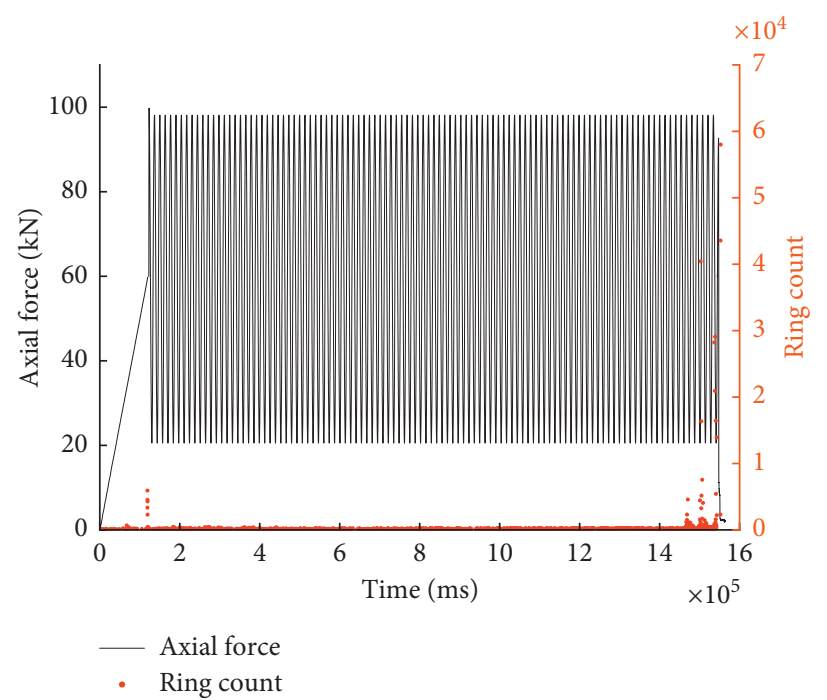

(c)

Figure 5: Acoustic emission evolution of sandstone under different loading frequencies. (a) Evolution of acoustic emission at $0.1 \mathrm{~Hz}$ frequency. (b) Evolution of acoustic emission at $0.2 \mathrm{~Hz}$ frequency. (c) Evolution of acoustic emission at $0.5 \mathrm{~Hz}$ frequency.

obviously different. The AE signals of sandstone under water saturation conditions were relatively sparse, which was obviously weaker than those under dry state and natural state. Under natural conditions, the water content of sandstone was relatively low, which was similar to that of sandstone after drying treatment. Therefore, the AE characteristics under natural conditions were basically similar to those under dry conditions. However, it can be seen that the $\mathrm{AE}$ activity of sandstone under dry conditions is stronger than that of sandstone under natural conditions. In addition, it can be seen from the sound produced by the failure of sandstone in three different water-saturated states that the dry and natural specimens emit strong noise, while the sound of saturated specimens is relatively weak. These phenomena showed that the water content has a great influence on the activity of AE: high water content reduces the brittleness of the specimen, which weakens the activity of $\mathrm{AE}$; low water content increases the brittleness of the specimen and enhances the activity of AE; that is, water content greatly affects the activity of $\mathrm{AE}$. The reason is that the rock fracture is mainly transgranular fracture and intergranular fracture. The moisture can soften and lubricate the specimen and reduce the connection between the rockforming grains and the mechanical strength of the grains, so that the energy needed to be injected into the rock during fracture is reduced. The more the water is, the more obvious this phenomenon is, and the $\mathrm{AE}$ activity of sandstone is obviously weakened. 


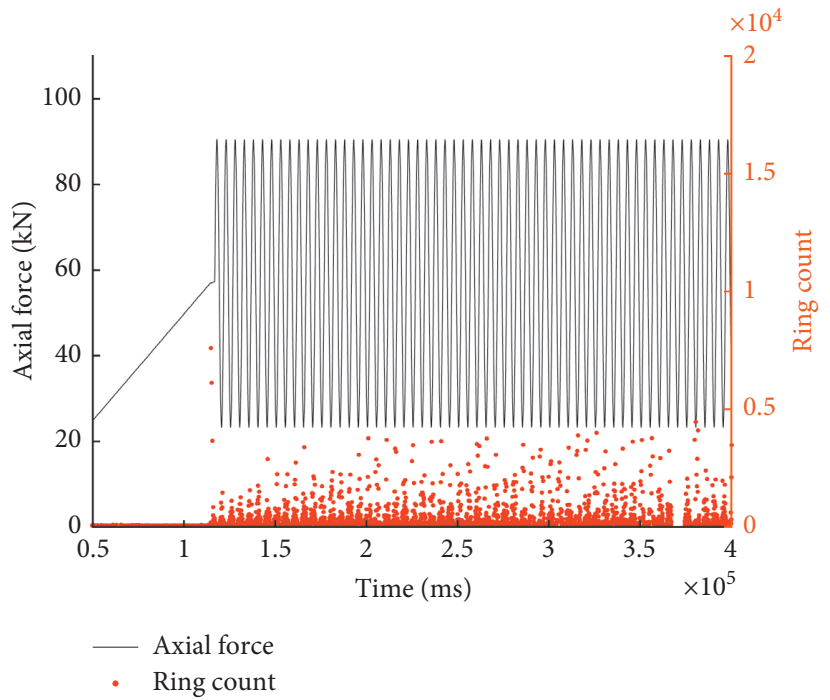

(a)

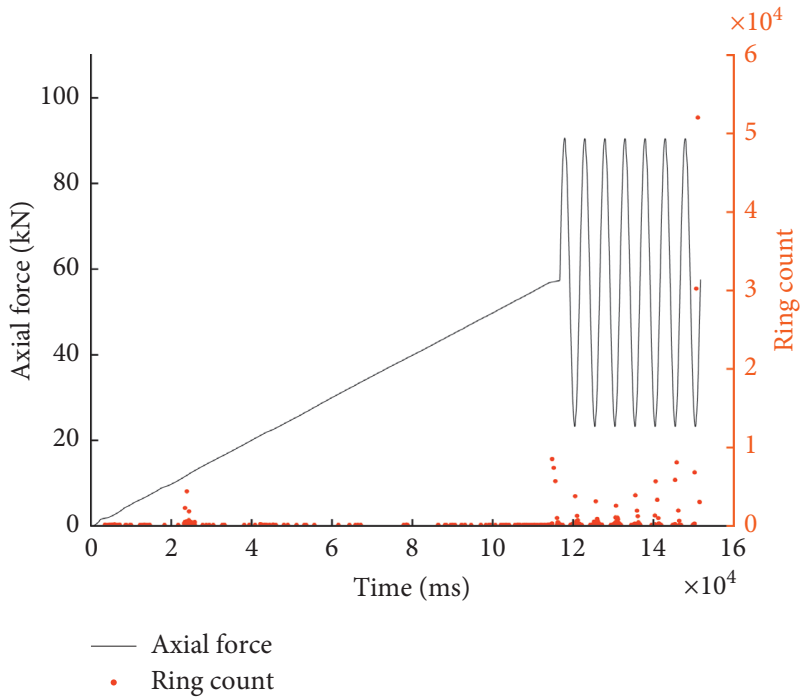

(b)

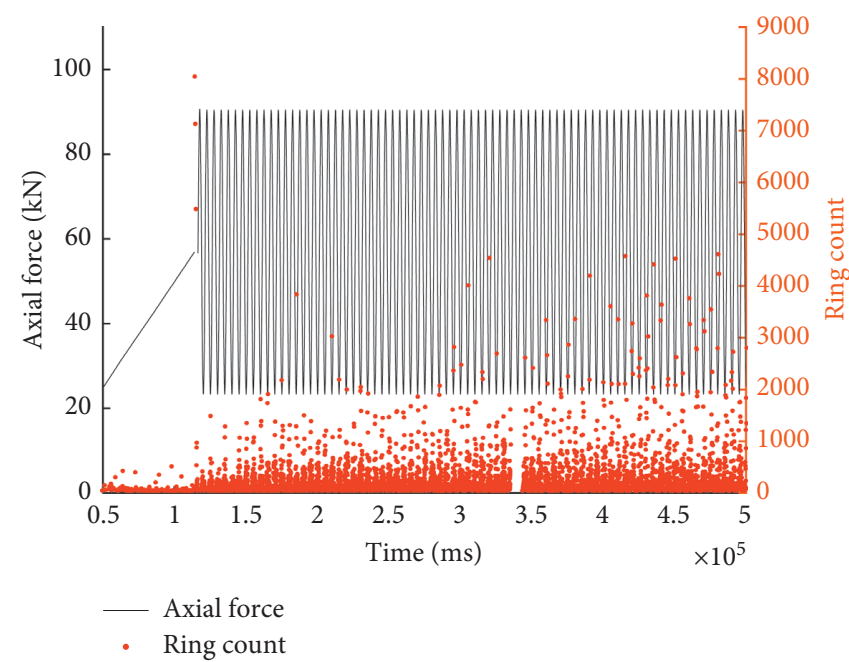

(c)

Figure 6: Acoustic emission evolution law of sandstone under different saturation conditions. (a) Evolution of acoustic emission in natural state. (b) Evolution of acoustic emission in saturated state. (c) Evolution of acoustic emission in dry state.

\section{Analysis of Resistivity Response Characteristics of Sandstone under Constant Amplitude Cyclic Loading}

4.1. Resistivity Characteristics of Sandstone under Different Stress Amplitudes. According to the test results, the axial force-time-resistivity curve of typical sandstone samples under different stress amplitude conditions is drawn, as shown in Figure 7. Under different stress amplitude loading conditions, the variation law of resistivity of sandstone specimen is basically the same as that of loading way. The specific performance was as follows: in the loading stage, the rock specimen was heterogeneous, and there were many microcracks and pores inside, which made the stress increase, the pores closed quickly, and the resistivity decreased rapidly; in the unloading stage, due to the decrease of stress, the compacted pores and microcracks gradually opened, and the resistivity increased. Generally speaking, the residual plastic deformation of the specimen occurred due to yield after each cycle of loading and unloading. The contact between mineral particles, the contact between skeleton and pore water, and the connectivity of water passage would be better than those of the previous cyclic loading. Therefore, with the development of cyclic loading, the resistivity of rock samples presented a gradual decline trend. But in the last few cycles, the specimen was on the verge of failure, the internal cracks accelerated to expand, the contact between skeleton particles became worse, and the rock resistivity presented a gradual increase process. When the fatigue life of the specimen was reached, the microcracks had penetrated into a large macrocrack, and the electrical resistivity increased suddenly when the specimen was destroyed.

At the same time, the test results also showed that the evolution characteristics of resistivity of different samples 


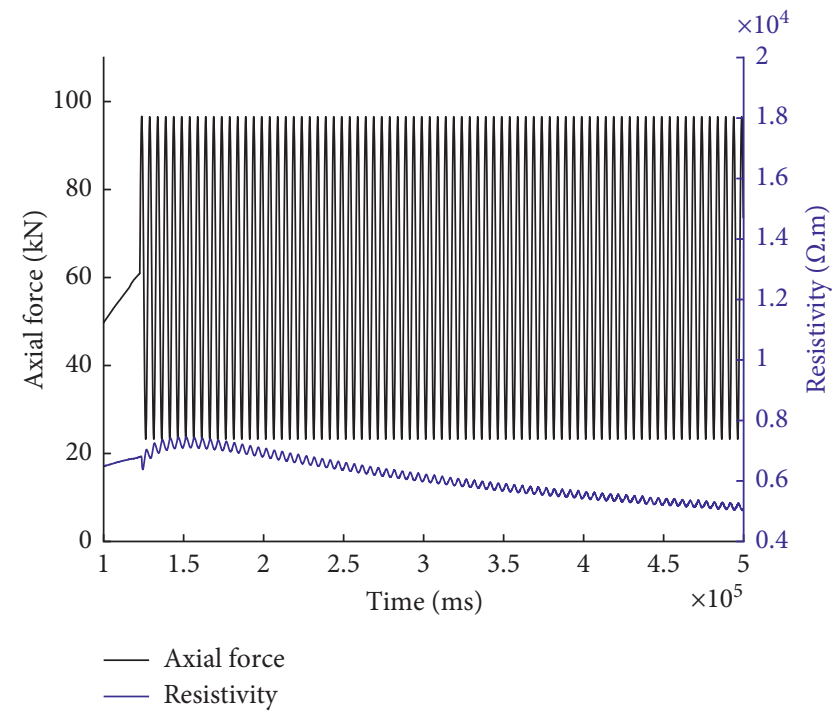

(a)

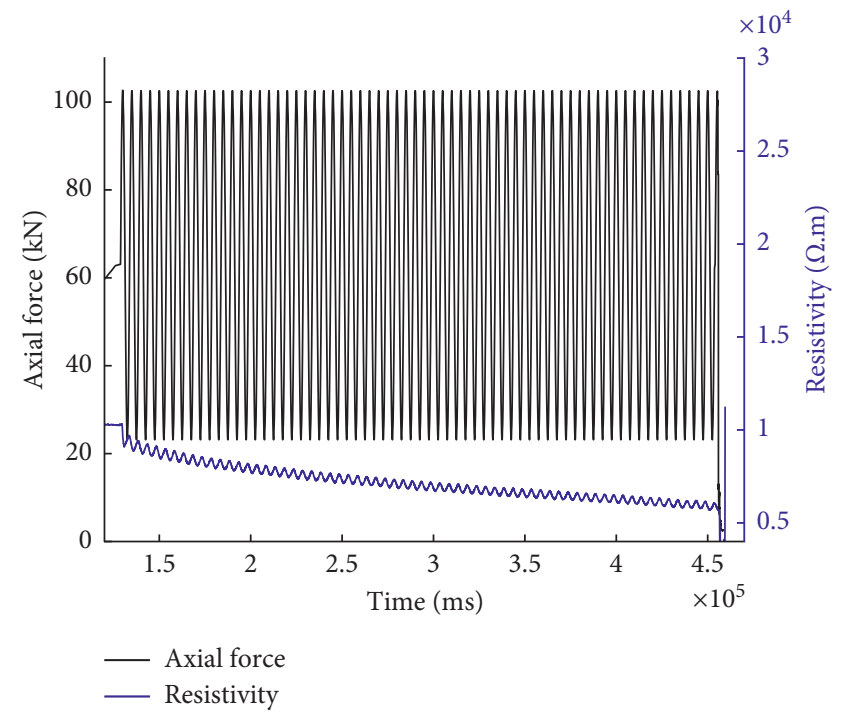

(b)

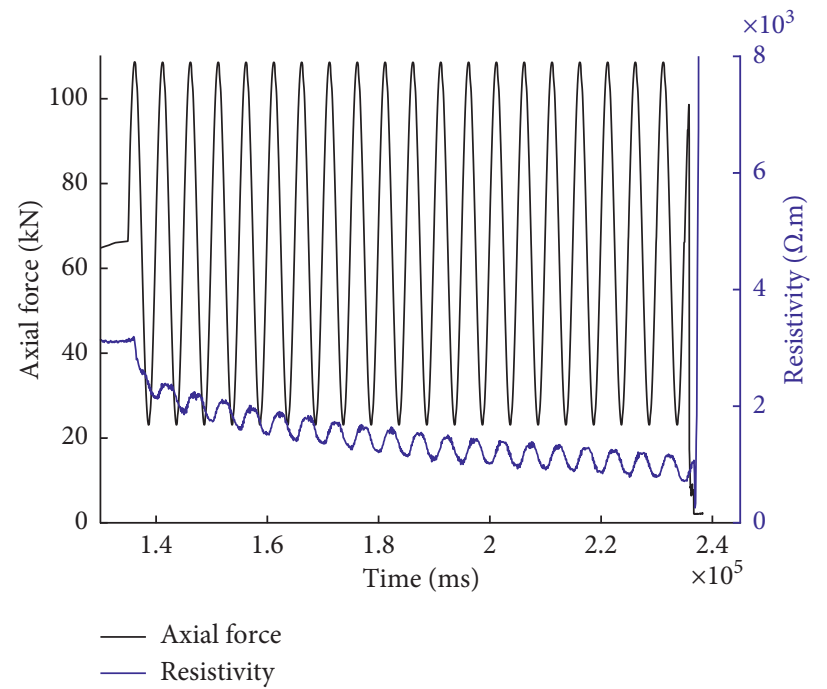

(c)

Figure 7: The resistivity evolution law of sandstone under different stress amplitude conditions. (a) Evolution of resistivity at $20 \%-80 \%$ stress level. (b) Evolution of resistivity at $20 \%-85 \%$ stress level. (c) Evolution of resistivity at $20 \%-90 \%$ stress level.

were different under different stress amplitude loading conditions. In the case of high-stress amplitude (when the stress level was $20 \%-85 \%$ and $20 \%-90 \%$ ), it can be seen that the resistivity decreased gradually from the beginning to the end of the cycle and then increased suddenly until the failure. However, when the stress level was between $20 \%$ and $80 \%$, the change of resistivity was different. The specific performance was as follows: within the initial several cycles, the resistivity increased gradually and then decreased gradually until the end of the cycle. The reason for this phenomenon is that when the stress level is $20 \%-80 \%$, the stress level is low and the yield strength of rock is not reached. At the initial cycle, the microcracks have begun to expand. During the whole loading and unloading process, the closing effect of microcracks is less than the crack propagation effect. The closing of microcracks leads to the decrease of resistivity, and the propagation of microcracks leads to the increase of resistivity. Therefore, the resistance first increases gradually and then decreases gradually after plastic residual deformation occurs for a certain number of cycles. When the stress amplitude continues to increase, the upper limit stress has exceeded the yield strength of rock, and each cycle will produce a certain amount of plastic residual deformation, which makes the resistivity continue to decrease.

In order to reflect the change rate of resistivity under different stress ratios, the change of resistivity is represented by the ratio $\left(\left(\rho-\rho_{0}\right) / \rho_{0}\right)$ of the difference of resistivity $\left(\rho-\rho_{0}\right)$ and initial resistivity $\left(\rho_{0}\right)$, and the resistivity change rate cycle number curve of the specimen was obtained, as shown in Figure 8. It can be seen that the change trend of resistivity analyzed above is well corresponding to this 


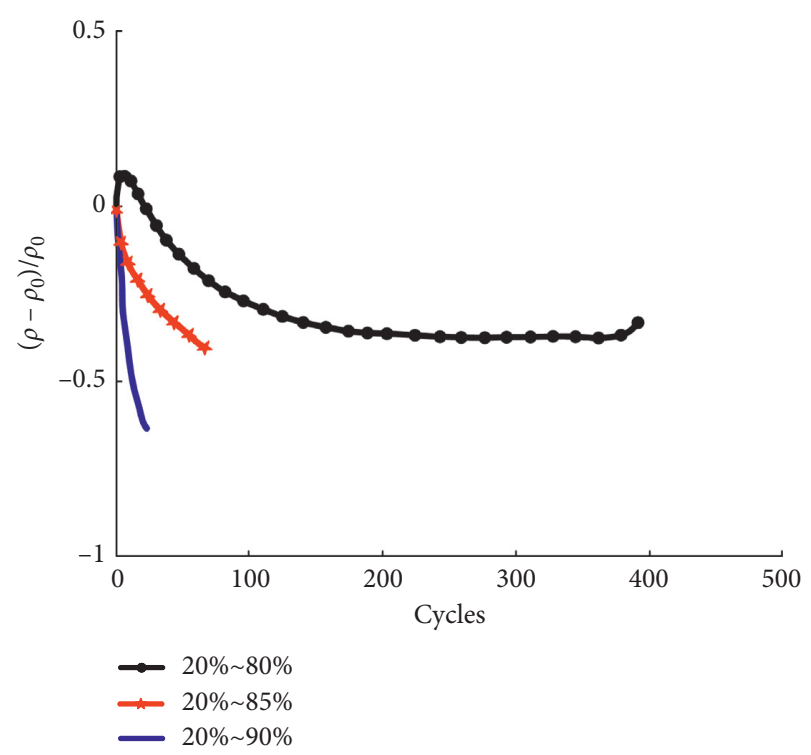

FIGURE 8: Resistivity evolution law of sandstone under different stress amplitudes.

diagram. If the previous several cycles are ignored, the variation trend of resistivity also conforms to the three-stage variation rule, which can be divided into initial stage, constant velocity stage, and acceleration stage. The resistivity decreases sharply at the beginning, then decreases gently at the constant speed stage, and increases gradually at the final acceleration stage. With the difference of stress amplitude, the proportion of each stage is different, which is consistent with the deformation law of sandstone. It can also be seen that the curve with high loading stress amplitude is always below the curve with low loading stress amplitude, which indicates that the resistivity change rate with high loading stress amplitude is higher than that with low loading stress amplitude in the same cycle times.

\subsection{Resistivity Characteristics of Sandstone under Different} Loading Frequencies. According to the test results, the axial force-time-resistivity curves of typical sandstone samples under different frequency loading conditions were drawn, as shown in Figure 9. The basic change trend of resistivity with stress was not changed under different frequency. In the loading stage, the internal porosity of the specimen decreased and the rock resistivity decreased; in the unloading stage, the internal closed cracks opened and the resistivity increased. However, the cyclic loading of specimens at different frequencies is at the same stress level, and the stress is the same, so the overall change trend of resistivity is different from that under different stress amplitude. Under different frequencies, the variation trend of the resistivity of sandstone specimens is basically the same from the beginning of the cycle to the failure stage. The resistivity gradually rises from the beginning of several cycles and then decreases after a few cycles. Finally, the resistivity suddenly increases when the specimen is damaged. Therefore, the different loading frequency has no effect on the overall change trend of resistivity at the same stress level.
The change of resistivity is still represented by the ratio $\left(\left(\left(\rho-\rho \_0\right) y \rho \_0\right)\right.$ of the difference of resistivity $\left(\rho-\rho \_0\right)$ and initial resistivity $\left(\rho \_0\right)$. The resistivity change rate cycle number curve was obtained, as shown in Figure 10. It can be seen that the curve with low frequency is always under the curve with high frequency. In the same cycle times, the resistivity with low frequency changes greatly, which indicates that the damage caused by the low loading frequency of each cycle is larger than that of the high loading frequency. This also explains why the lower the loading frequency is, the longer the cycle of the sample is.

\subsection{Resistivity Characteristics of Sandstone under Different} Saturations. According to the test results, the axial forcetime-resistivity relationship curves of typical sandstone samples under different saturation conditions were drawn, as shown in Figure 11. The water content had a great influence on the resistivity of sandstone specimens. It can be seen that the resistivity of sandstone in saturated state was only a few hundred $\Omega \cdot \mathrm{m}$, but the resistivity of natural state specimen was relatively high due to its small water content, which could reach several thousand $\Omega \cdot \mathrm{m}$. After drying, the resistivity of the dry specimen had reached tens of thousands $\Omega \cdot m$, which was mainly because the dry specimen has almost no moisture, and the current could only be conducted through the rock skeleton particles with weak conductivity, so that the resistivity of the dry specimen was relatively high. With the increase of saturation, the water content of the specimen was also increasing. Water is very easy to conduct electricity, which greatly improves the conductivity of the whole specimen, so the resistivity of the specimen decreases rapidly with the increase of saturation. Therefore, the moisture content is a very important factor affecting the resistivity of the specimen.

It can be seen that the evolution trend of resistivity of saturated samples under load is as follows: in the initial linear loading stage, the resistivity gradually decreases, which may be because the saturated samples are not really saturated but still have certain voids. With the increase of loading stress, the pores are closed, so the resistivity tends to decrease. Then the resistivity increases gradually, which may be due to the gradual seepage of mineralized water in the pores after the pores are compacted. When the stress reaches a certain value, microcracks and fracture surfaces are produced in different degrees, and air entry leads to an increase in resistivity. After entering the cyclic loading process, due to the sharp increase of stress, the initial cyclic loading resistivity changes greatly, and then the resistivity presents an increasing process with the increase of the number of cycles. This is because the strength of the rock will decrease sharply after the specimen is saturated with water, and the upper limit stress ratio of $75 \%$ is determined by the compressive strength of the rock under natural state. For water-saturated specimens, the upper limit stress ratio has exceeded the yield strength or even close to the peak strength, which makes more fractures and fracture surfaces appear in each cycle, so the resistivity of sandstone shows a trend of gradual increase. However, the specimen in the natural state will produce a certain plastic residual deformation after each cycle. The contact 


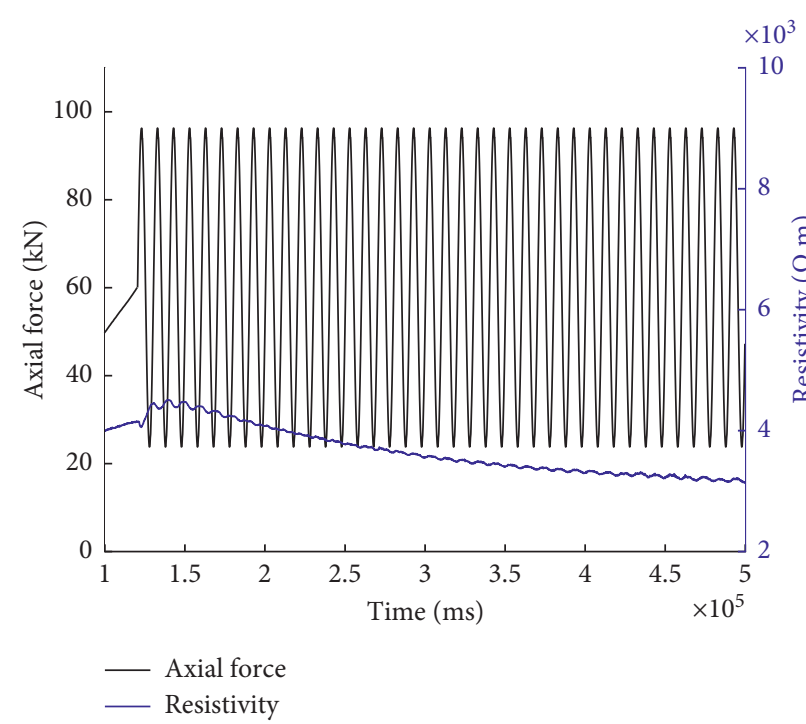

(a)

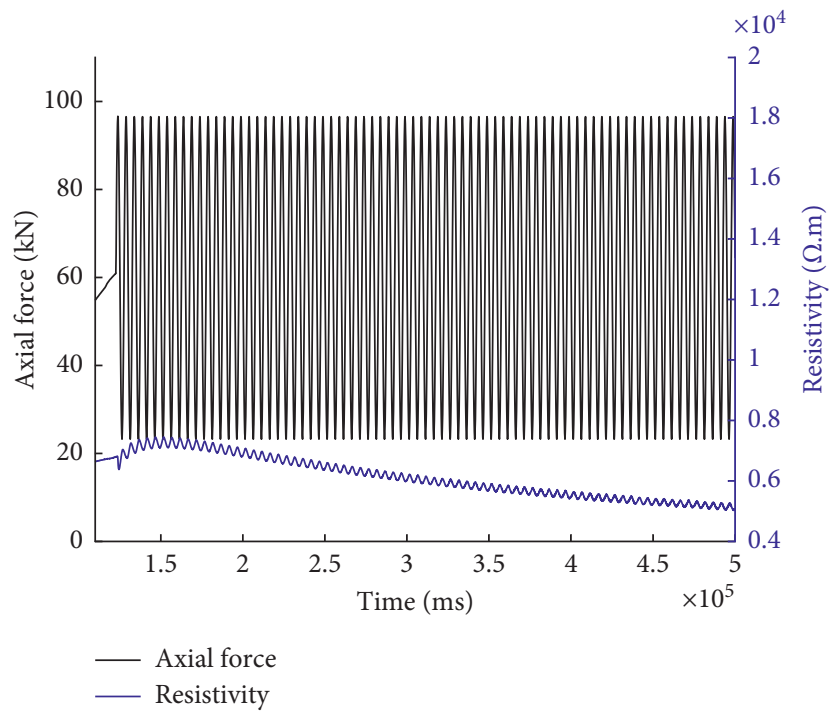

(b)

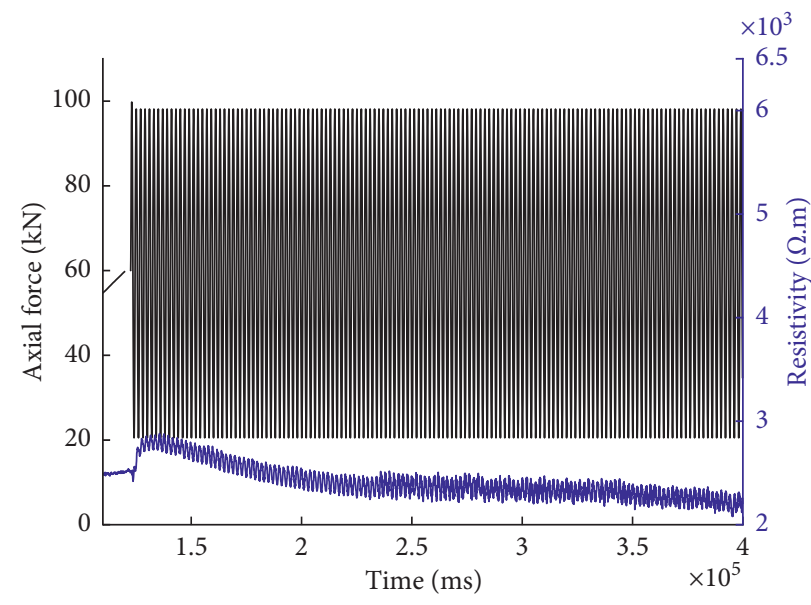

- Axial force

- Resistivity

(c)

FiguRe 9: Resistivity evolution of sandstone under different loading frequencies. (a) Resistivity evolution law of frequency at $0.1 \mathrm{~Hz}$. (b) Resistivity evolution law of frequency at $0.2 \mathrm{~Hz}$. (c) Resistivity evolution law of frequency at $0.5 \mathrm{~Hz}$.

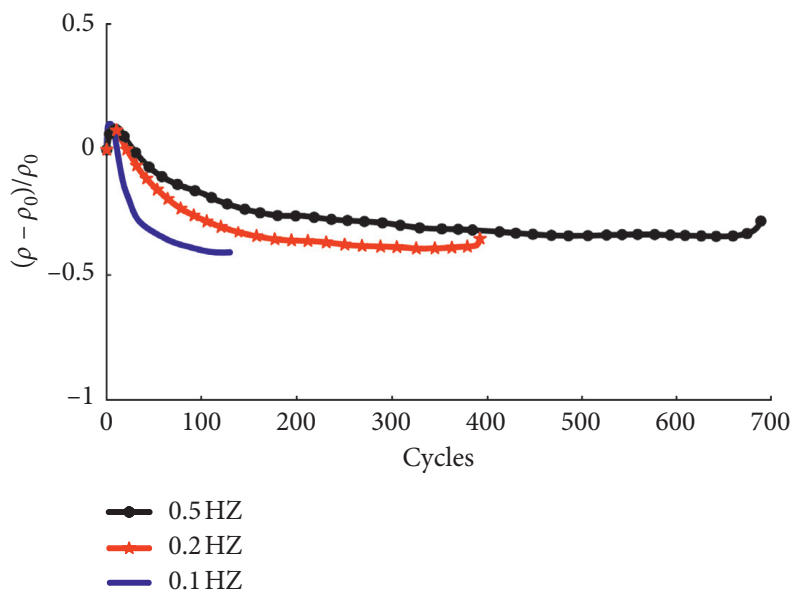

FIGURE 10: Variation of resistivity at different frequencies. 


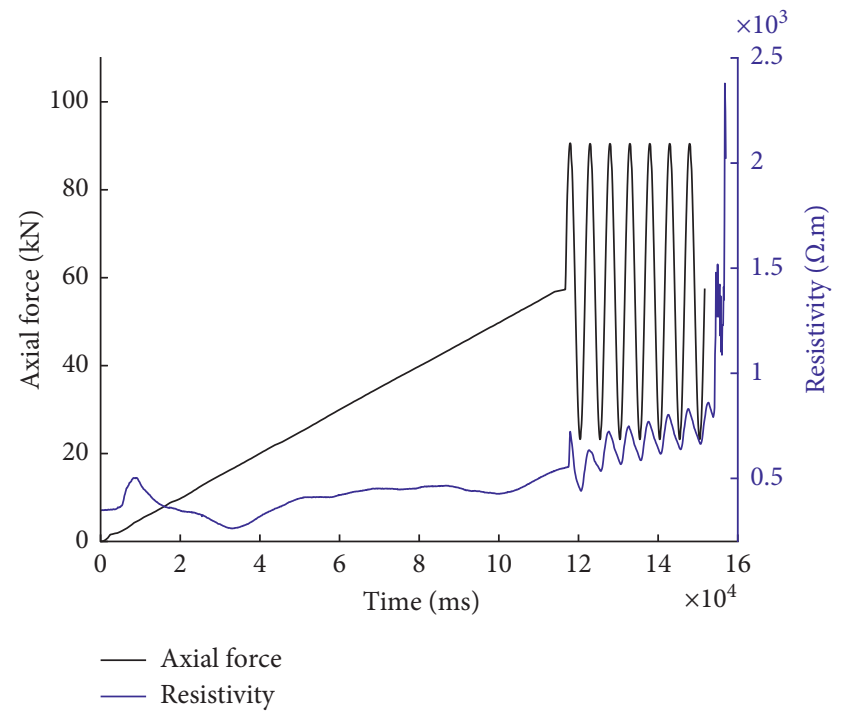

(a)

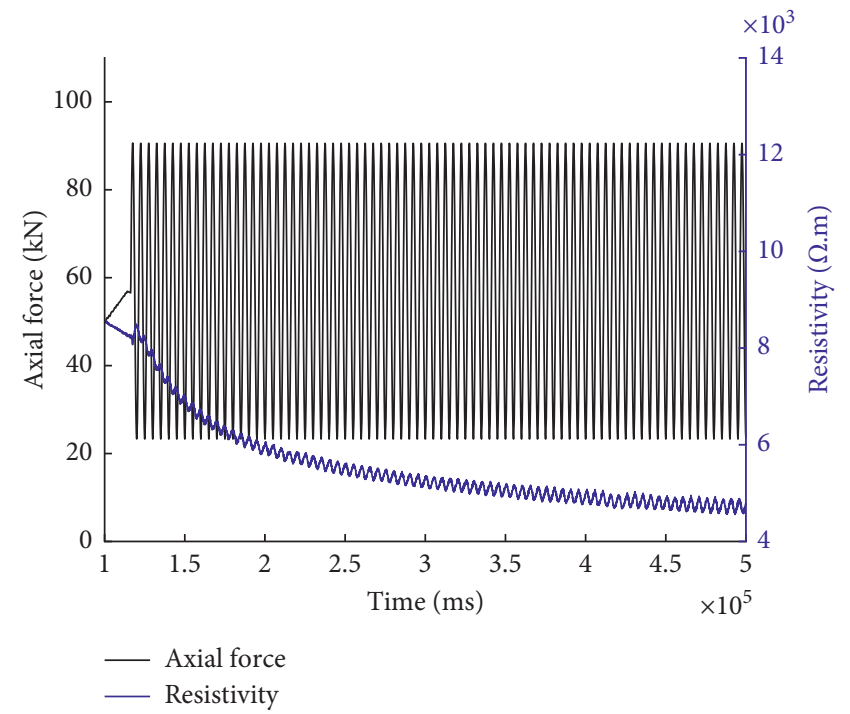

(b)

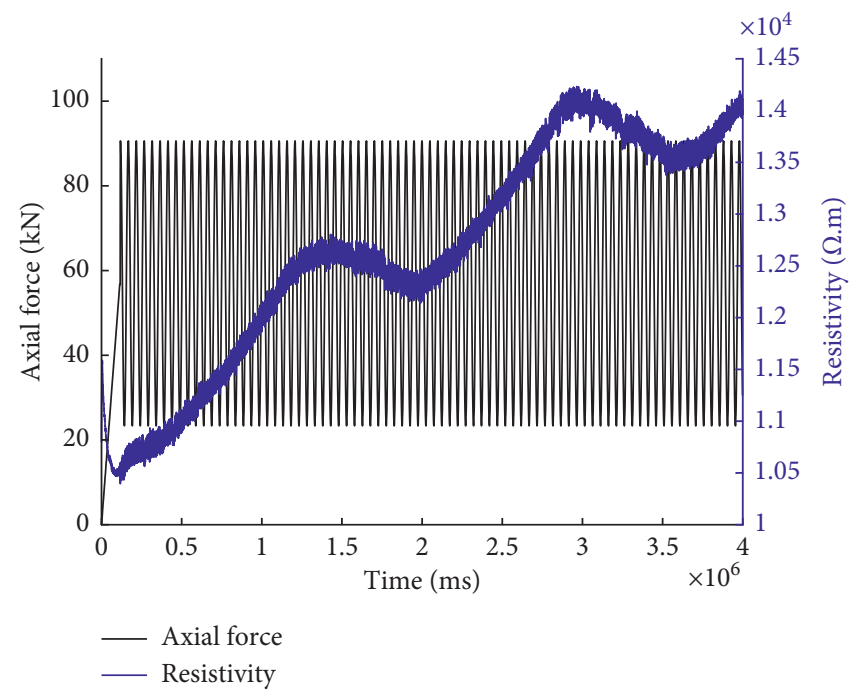

(c)

FIGURE 11: Resistivity evolution of sandstone under different saturation conditions. (a) In saturated state. (b) In natural state. (c) In dry condition.

between the mineral particles and the contact between the skeleton and the pore water will be better than the previous cycle loading. As the loading progresses, the resistivity of the rock specimen shows a gradual decline in evolution trend. In the dry state, the water content of the specimen is almost zero, and the strength is greatly increased, so it has not been damaged even after 2,000 cycles. At the same time, the changing law of resistivity is also quite different. After the initial decline in resistivity, it shows periodic changes (rising-falling-rising-falling) as the number of cycles increases. This may be due to the periodic expansion and closure of microcracks. Due to the time, this test failed to compress the dry specimen to failure. The change trend of the resistivity later is unknown. It is inconvenient to analyze the specific reason. It is hoped that the follow-up researchers can press it to destruction and then analyze the specific reasons in detail through the change trend of resistivity in the whole destruction process.

\section{Conclusion}

In this paper, the AE-resistivity-stress synchronous test experiment of sandstone is carried out to analyze the evolution of $\mathrm{AE}$ and resistivity of sandstone under constant amplitude cyclic loading. The main conclusions are as follows:

(1) Under the condition of constant amplitude cyclic loading, the evolution law of $\mathrm{AE}$ of sandstone corresponds to the three stages of rock fatigue deformation, and the change law of resistivity is basically the same as the way of loading. The magnitude of the stress 
amplitude has a significant impact on the $\mathrm{AE}$ and resistivity evolution law of sandstone. Specifically, as the stress amplitude increases, the AE activity increases, and the $\mathrm{AE}$ ringing count generated increases. When the stress amplitude is relatively high, the resistivity will gradually decrease from the beginning of the cycle to the end of the cycle, until the resistivity suddenly increases when the stress is broken, and when the stress amplitude is relatively low, the resistivity first gradually increases, and then the resistivity gradually decreases as a whole. Generally, the resistivity evolution rate of the specimen with high loading stress amplitude is higher than that of the specimen with low loading stress amplitude.

(2) The loading frequency has a greater impact on the AE activity of sandstone. The higher the loading frequency, the smaller the rock damage caused by each cycle, the weaker the AE signal produced, and the less the ringing count per unit time. However, the different loading frequency has no effect on the overall variation trend of resistivity under the same stress level. The resistivity increases gradually from the beginning of several cycles, then decreases gradually after a few cycles, and finally increases suddenly when the failure occurs. And the lower the loading frequency, the faster the resistivity change rate.

(3) Saturation has a significant influence on AE activity and electrical resistivity of rocks. Saturation represents the level of water content. The higher the water content, the weaker the AE activity; otherwise, the stronger the AE activity. After entering the cyclic loading process, the resistivity of water-saturated specimens changes greatly in the initial stage, and the resistivity increases with the increase of the number of cycles. However, the resistivity of the specimens in natural state decreases gradually. In the dry state, after the initial decline in resistivity, the later period showed a periodic change (up-down-up-down) as the number of cycles increased.

\section{Data Availability}

The data used to support the findings of this study are available from the corresponding author upon request.

\section{Conflicts of Interest}

The authors declare that they have no conflicts of interest.

\section{Acknowledgments}

The authors gratefully acknowledge the financial supports from the Natural Science Foundation Project of China (Grant no. 51609027), and Innovative Research Program of Chongqing Jiaotong University (Grant no. 2020S0024), and
Science and Technology Projects of Department of Transportation of Jiangxi Province (Grant no. 2019Q0027).

\section{References}

[1] L. Obert and W. I. Duvall, Micro-seismic Method of Determining the Stability of Underground openings[R], United States Department of the Interior, Washington, DC, USA, 1957.

[2] P. Ganne, A. Vervoort, and M. Wevers, "Quantification of pre-peak brittle damage: correlation between acoustic emission and observed micro-fracturing," International Journal of Rock Mechanics and Mining Sciences, vol. 44, no. 5, pp. 720-729, 2007.

[3] V. L. Shkuratnik, Y. L. Filimonov, and S. V. Kuchurin, "Regularities of acoustic emission in coal samples under triaxial compression," Journal of Mining Science, vol. 41, no. 1, pp. 44-52, 2005.

[4] P. Rodríguez and T. B. Celestino, "Application of acoustic emission monitoring and signal analysis to the qualitative and quantitative characterization of the fracturing process in rocks," Engineering Fracture Mechanics, vol. 210, pp. 54-69, 2019.

[5] L. J. Wang, B. Zhang, Z. K. Qian et al., "Experimental investigation of the acoustics emission Characteristics of two types of brittle rocks under uniaxial compression," Journal of Engineering Geology, vol. 27, no. 4, pp. 699-705, 2019.

[6] Y. Jiang, X. Ge, and J. Ren, "Deformation law and acoustic emission characteristics of rock during fatigue failure," Journal of Rock Mechanics and Engineering, vol. 23, no. 11, pp. 1810-1814, 2004.

[7] X. Wang, H. Ge, L. song, hetaiming, and X. Wei, "Experimental study on two types of rock acoustic emission events and Kaiser effect point identification method," Chinese Journal of Rock Mechanics and Engineering, vol. 30, no. 3, pp. 580-588, 2011.

[8] Y. Song, T. Xing, T. Zhao, Z. Zhao, and P. Gao, "Study on acoustic emission characteristics of rock uniaxial compression deformation field evolution," Journal of Rock Mechanics and Engineering, vol. 36, no. 03, pp. 534-542, 2017.

[9] G. E. Archie, "The electrical resistivity log as an aid in determining some reservoir characteristics," Transactions of the AIME, vol. 146, no. 1, pp. 54-62, 1942.

[10] O. A. L. Lima, B. C. Michael, G. N. Geraldo et al., "A volumetric approach for the resistivity response of freshwater shaly sandstones," Geophysics, vol. 70, no. 1, pp. F1-F10, 2005.

[11] T. Masao, Y. Isao, and F. Yoshio, "Anomalous electrical resistivity of almost dry marble and granite under axial compression," Journal of Physics of the Earth, vol. 41, no. 6, pp. 337-346, 1993.

[12] G. Chen and Y. Lin, "Stress-strain-electrical resistance effects and associated state equations for uniaxial rock compression," International Journal of Rock Mechanics and Mining Sciences, vol. 41, no. 2, pp. 223-236, 2004.

[13] W. F. Brace and A. S. Orange, "Electrical resistivity changes in saturated rock under stress," Science, vol. 153, no. 3743, pp. 1525-1526, 1966.

[14] S. Kahraman and T. Yeken, "Electrical resistivity measurement to predict uniaxial compressive and tensile strength of 
igneous rocks," Bulletin of Materials Science, vol. 33, no. 6, pp. 731-735, 2010.

[15] H. Ji, P. Xiang, L. Zhang et al., "Experimental study and detection analysis of mechanical property variation of mining disturbed rock mass," Journal of Rock Mechanics and Engineering, vol. 30, no. 11, pp. 2 352-2 359, 2011.

[16] J. Song, Z. Li, B. Liu et al., "Study on resistivity response law of limestone samples during constant amplitude and graded cyclic loading and unloading," Journal of Rock Mechanics and Engineering, vol. 34, no. S2, pp. 3880-3887, 2015.

[17] J. Tu, Q. sun, Z. Jiang et al., "Apparent resistivity change and stress ratio of brittle critical failure of rock," Acta Sinica Sinica, vol. 38, no. 2, pp. 221-225, 2013. 